\title{
Jovem, dedicado, confinado e prejudicado: perfis, rotinas e processos jornalísticos durante a pandemia de Covid-19
}

\section{Young, dedicated, confined and hindered: profiles, routines and processes of journalists during the Covid-19 pandemic}

Edson Capoano'

\section{Vanessa Teixeira de Barros²}

\section{Resumo}

O trabalho caracteriza perfis profissionais e rotinas produtivas de jornalistas envolvidos na cobertura da pandemia do novo Coronavírus em junho de 2020. 0 corpo teórico versa sobre processos produtivos, perfis profissionais e rotinas de trabalho nas redações. A metodologia utilizada é a revisão bibliográfica para geração de inquérito e a composição deste para coleta de amostra nãoprobabilística. Conclui-se que o perfil médio da mostra é de um jovem de São Paulo que, ao trabalhar em home office, aumentou seu tempo de dedicação, produziu notícias sobre Covid-19 mesmo sem especialização no tema, utilizou duas a três fontes por conteúdo, e sofreu algum constrangimento ou impedimento para realizar o ofício jornalístico.

\footnotetext{
' Doutor em Comunicação e Cultura pelo PROLAM-USP; Mestre e Bacharel em Comunicação Social pela PUC-SP; Investigador do Centro de Estudos de Comunicação e Sociedade - CECS, da Universidade do Minho. edson.capoano@ics.uminho.pt

${ }^{2}$ Mestre em Jornalismo Profissional pelo Centro Universitário Fiam-Faam; Graduada em Jornalismo pela Universidade Presbiteriana Mackenzie. vanessabarros.jor@gmail.com
} 
Palavras-chave: Jornalismo. Perfis profissionais. Processos produtivos.

\section{Abstract}

The work features professional profiles and productive routines of journalists involved in the coverage of the new Coronavirus pandemic in June 2020. The theoretical body deals with production processes, professional profiles and work routines in newsrooms. The methodology used is the bibliographic review for generating a survey and its composition for collecting a non-probabilistic sample. It is concluded that the average profile of the show is that of a young man from São Paulo, who, working at home office, increased his dedication time, produced news about Covid-19 even without specialization in the subject, used two to three sources per content, and suffered some constraint or impediment to carry out the journalistic craft.

Keywords: Journalism. Professional profiles. Productive processes.

\section{Introdução}

Em dezembro de 2019, um surto de síndrome respiratória aguda grave (SARS) foi identificado em Wuhan, na China. Em semanas, este novo vírus já havia alcançado outros países, causando pneumonia em massa graças a sua infeção pulmonar severa (ZU et al., 2020, p. 200490). A 30 de janeiro de 2020, a Organização Mundial da Saúde (OMS) nomeou a doença "doença do coronavírus 2019" (Co-Vid-19) (VELAVAN ; MEYER, 2020, s.p.) e a 11 de março de 2020, declarou que o contágio do novo coronavírus havia evoluído para uma pandemia ${ }^{3}$, com "níveis alarmantes de propagação e inação" (GHEBREYESUS, 2020, s.p.). Desde então, praticamente todos países do globo e suas sociedades travam uma batalha de resiliência contra a doença e seus efeitos na saúde, no sistema hospitalar, na economia e na política ${ }^{4}$.

Tal mobilização mundial não tem referência em nenhum outro acontecimento no século XXI, no que tange ao impacto nas agendas individuais, governativas e empresariais (MOLLA, 2020 , s.p.), ao ponto de pensadores da sociedade global avaliarem a pandemia do novo coronavírus e a Covid-19 como o evento que inaugurou o século XXI (SCHWARCZ, 2020, s.p.); o fim de modelos da humanidade estabelecidos (GIL, 2020, s.p.), com alternativas

\footnotetext{
${ }^{3}$ A definição da expressão, segundo De Rezende (1998, s.p.), é de "uma epidemia de grandes proporções, que se espalha a vários países e a mais de um continente".

${ }^{4}$ Segundo a OMS, "os países podem ainda mudar o curso desta pandemia se detectarem, testarem, tratarem, isolarem, rastrearem e mobilizarem as pessoas na resposta" (GHEBREYESUS, 2020, s.p.).
} 
aos modelos de sociedade trazidas pela crise sem precedentes (SANTOS, 2020, s.p.), com tempo de privações materiais e deflagração de descontentamentos sociais (GIANNETTI, 2020, s.p.); um ponto e vírgula na acumulação desenfreada de capital (WISNIK, 2020, s.p.) e na normalidade opressora do capitalismo (ZIZEK, 2020, s.p.), inclusive da finitude dos recursos naturais, econômicos e sociais para as elites econômicas, que estão "na fila do pão" (SCURATI, 2020, s.p.); o ensaio para a grande crise climática por vir (MEIRELLES, 2020 , s.p.) e de possível legado de depressão e demais doenças mentais pelo confinamento forçado (SOLOMON, 2020, s.p.), mas também um momento de decisões que definirão nosso futuro (HARARI, 2020, s.p.), bem como se as vidas de milhões de pessoas ceifadas pela pandemia terão sido em vão (KRENAK, 2020, s.p.).

Nesse ínterim, das milhares de categorias profissionais que tiveram que adaptar-se ao que chamam "novo normal", uma série de procedimentos para evitar a contaminação pelo novo coronavírus, estão os jornalistas, considerados grupo de atividade essencial em muitas sociedades, em tal momento de desinformação e insegurança. Este trabalho tem como objetivo caracterizar os perfis dos profissionais envolvidos na cobertura da pandemia, identificar as alterações nas suas rotinas de trabalho e compreender seus processos produtivos. Esta proposta foi elaborada a partir dos primeiros resultados de um estudo intitulado "Percepção sobre as informações geradas durante o Covid-19" (CAPOANO; COSTA, 2020), que busca compreender como as restrições sociais causadas pela pandemia do novo Coronavírus, como o afastamento e o isolamento sociais e as diversas formas de quarentena impostas às sociedades no mundo inteiro, causaram alterações nos processos informativos de produtores e receptores e na criação das mensagens noticiosas durante o período.

\section{Desenvolvimento}

\section{Metodologia}

Estipulou-se que o estudo teria três etapas, com o foco em cidades cujas praças de produção e consumo de jornalismo fossem mais representativas aos seus respectivos países: do Brasil, São Paulo, com coleta de dados durante o mês de junho de 2020; de Portugal, com coleta durante julho; e dos países da CPLP, suas capitais (Comunidade dos Países de Língua Portuguesa), em agosto. Tal recorte geográfico se dá pela importância nos estudos sobre a Lusofonia (MARTINS, 2015, p.5), ambiente cultural com mais de 260 
milhões de pessoas, segundo o Instituto Camões (2019, s.p.). Até agora, devido às limitações e imposições ocasionadas pela pandemia, conseguiu-se concluir apenas a primeira etapa.

Como delimitação do corpus na primeira etapa do estudo, escolheu-se abordar jornalistas e consumidores regulares de informação de São Paulo, alcançados pela plataforma Facebook, direcionada com os temas de interesse "jornalistas" e "jornalismo"-, além da página pessoal de um dos autores deste trabalho, que conta com 3244 membros até a produção deste texto, na maioria jornalistas, atuantes na imprensa de São Paulo e em empresas de mídia e produção de conteúdo, além de consumidores regulares de notícias, inseridos em grupos de discussão sobre o tema.

A coleta de informações foi realizada por meio de formulário online sediado e disponibilizado pela plataforma Google Forms, com disparo de convites pela plataforma Messenger e pela ferramenta FB Message Sender, para coletar respostas sobre perguntas pré-estruturadas e respostas na escala Likert (1 a 5 pontos entre discordância e concordância). O inquérito, inspirado nos estudos sobre perfis de jornalistas (FIGARO, 2013; FIGARO, NONATO ; GROHMANN, 2013; MICK ; LIMA, 2013), e em conceitos como processos produtivos (ADGHIRNI, 2010), (DEUZE; WITSCHGE, 2016), rotinas de trabalho (HELOANI, 2006) e critérios de noticiabilidade (MESQUITA, 2003; TRAQUINA, 2005; WOLF; DE FIGUEIREDO, 1987), é constituído por 21 perguntas específicas para jornalistas e possui questões acerca do perfil dos respondentes (faixa etária, gênero); dados profissionais (tempo de profissão, tipo de meio de comunicação que atua, editoria e empresa); rotina de trabalho durante a pandemia (alterações na carga horária, local de trabalho, equipamentos de proteção, impedimentos no trabalho e constrangimentos); processos produtivos (tipo e número de fontes de informações; formato; gênero; critérios de noticiabilidade); e contato com a doença (se foram infectados ou conhecem quem foi).

A metodologia se deu pela escolha da realização de um inquérito com amostra nãoprobabilística, constituído por 365 respostas (das quais, 227 formam as válidas) obtidas durante o mês de junho ${ }^{5}$. Cerca de $33,4 \%$ provém de jornalistas produtores de informação durante o fenômeno, $32,6 \%$ de jornalistas não atuantes no ofício e $29,5 \%$ de não jornalistas consumidores regulares de jornalismo. Para caracterizar os perfis profissionais dos

\footnotetext{
${ }^{5}$ Quantidade obtida por meio de duas versões do inquérito, em português e em espanhol.
} 
jornalistas envolvidos na cobertura da pandemia e compreender os processos de produção jornalística, o trabalho apresentado aqui concentra a análise maioritariamente nos dados dos respondentes que se identificaram como "jornalistas atuantes" (227 respostas), sejam titulados ou não.

Os resultados coletados serão apresentados a seguir, organizados segundo três grupos temáticos: os perfis dos respondentes, composto pelos tópicos etário (quando se esclarecem sua idade e em qual corte geracional estão incluídos), temporal (os anos de carreira em jornalismo) e laboral (qual a natureza do veículo de comunicação no qual trabalham e as editorias nas quais se dedicaram); o grupo de questões relacionadas às rotinas de trabalho, composto pelos tópicos tempo de dedicação durante a pandemia (se cresceu o número de horas semanais de dedicação ao ofício), limitações ou impedimentos impostos à prática da profissão, e o grupo processos produtivos, com os tópicos tipo de conteúdo produzido (formato e conteúdo), forma de checagem dos dados coletados e fontes utilizadas (sobre quantidade e natureza destas).

\section{Resultados}

\section{Perfil profissional}

Os dados coletados confirmam que mais da metade da amostra $(53,2 \%)$ é de jovens jornalistas entre 26 a 40 anos; um quarto da amostra é composta por pessoas entre 41 a 55 anos; e os mais jovens, entre 18 a 25 anos somam 12,1\% da amostra (365 respostas, 227 válidas).

Em relação ao tempo de carreira, 35,8\% trabalham entre 1 a 5 anos, e 20,9\% trabalham entre 6 a 10 anos. Somando esses resultados temos a maioria $(56,7 \%)$ dos jornalistas respondentes na primeira década de carreira (365 respostas, 227 válidas).

Na seção correspondente ao meio de comunicação dos jornalistas atuantes, $50,8 \%$ da amostra trabalha especificamente em veículos de informações noticiosas, entre eles: web (14,7\%); meios impressos (11,7\%); agência de notícias (7\%); rádio $(8,8 \%)$; TV $(5,8 \%)$ e correspondentes, (2,9\%) (365 respostas, 227 válidas).

Para classificar as editorias em que atuam os nossos respondentes, consideramos para análise apenas as editorias citadas pelos profissionais atuantes em meios de informação noticiosa. Logo, das 45 editorias válidas identificadas, 11,1\% correspondem à economia; 
8,8\% de política; $6,6 \%$ sobre a editoria de saúde; e 2,2 \% de ciência (365 respostas, 227 válidas).

\section{Rotinas de trabalho}

Assim como diversos trabalhadores essenciais, os jornalistas se debruçaram em muitos esforços para manter a população informada, muitos deles enfrentando o risco de serem contaminados pelo vírus e encarando condições precárias de trabalho. Em nossa amostra, 95,4\% declararam ter sofrido algum tipo de alteração na rotina de trabalho, entre elas, a adoção do regime de teletrabalho, resposta de $65,7 \%$ dos inquiridos. $01 / 3$ restante da amostra se distribui entre $8,7 \%$ de repórteres na rua e $23,4 \%$, que continuam em trabalho presencial na empresa jornalística (365 respostas, 227 válidas). Os dados da nossa amostra indicam que $64,9 \%$ dos respondentes declararam terem recebido EPIs (equipamento de proteção individual) das empresas que trabalham, ainda que não possamos identificar se a parcela dos respondentes em mobilidade corresponde aos que foram amparados pelos equipamentos cedidos. Somente um terço dos respondentes não tiveram alterações no tempo de trabalho diário. Enquanto 23,3\% declarou estar trabalhando menos durante a pandemia, metade deles $(51,12 \%)$ passou a trabalhar mais horas por dia (365 respostas, 227 válidas). Além das condições precárias na rotina, quase $20 \%$ dos respondentes foram impedidos de exercer a sua atividade laboral de algum modo. Dentro dessa amostra, metade deles tiveram o acesso a locais ou a documentos negados, e $34 \%$ passaram por situações de ameaça verbal em algum momento da cobertura (365 respostas, 227 válidas).

\section{Processos produtivos}

Ainda que nossa amostra se distribuísse em pelo menos 45 editorias mencionadas, $75,7 \%$ dos respondentes produziram informação sobre a Covid-19 independente da editoria que cada profissional estava debruçado anteriormente (365 respostas, 227 válidas). Sobre o formato que produziram, $55,9 \%$ dos respondentes se referem a texto (seja ele para web, ou versões impressas); $15,5 \%$ produziram para o rádio; vídeos foram produzidos por $12,3 \%$ da amostra; $9,6 \%$ produziram fotos; e somente 4,3\% debruçaram-se a gráficos ou infográficos. Na amostra, $90 \%$ dos respondentes declararam exercer a verificação de dados 
primordialmente pela web (365 respostas, 227 válidas). Em relação à fonte, a maioria (65\%) utilizou duas (35\%) ou três (30\%) fontes por conteúdo médio produzido. Metade da amostra usou como checagem de dados coletados a combinação de fontes oficiais $(27,5 \%)$; com especialistas $(22,4 \%)$. Aqui, as principais fontes consultadas e citadas como oficiais e especialistas se referem à Organização Mundial da Saúde - OMS, ministérios da saúde de governos municipais, estaduais e federais, profissionais de saúde (médicos e enfermeiros) e cientistas (pesquisadores, infectologistas e epidemiologistas) (365 respostas, 227 válidas).

\section{Análise}

A distribuição por gênero dos respondentes de nossa amostra foi praticamente idêntica, diferente de estudos similares, como o que realizaram Mick e Lima (2013), em "Perfil do jornalista brasileiro - Características demográficas, políticas e do trabalho jornalístico em 2012", em que sua amostra é maioritariamente feminina (64\%) e jovem (59\% têm até 30 anos). Assim, ainda que consideremos que as redações de imprensa e de mídia estão compostas por maior índice de mulheres, o resultado de nossa amostra não contamina os resultados, dado que o empate técnico entre respostas anula essa questão em relação às demais do inquérito.

Entendemos, contudo, que as mulheres jornalistas deveriam ter uma análise mais aprofundada, dado que há aspectos que recaem majoritariamente sobre elas, como a dupla jornada de trabalho e atribuições (ditas maternais, em nossa sociedade patriarcal), que não foram consideradas neste trabalho, mas que farão diferença considerável nos processos produtivos e nas rotinas de produção para as profissionais. As questões identitárias e emocionais desse grupo, por sua vez, podem precarizar ainda mais sua condição durante tal período de exceção como o vivido em 2020.

Quanto ao tempo de carreira e tempo gasto na rotina laboral, na amostra nota-se o reflexo de uma das transformações decorrentes da convergência nas redações, registrada por Adghirni (in MOUILLAUD; PORTO, 1997, p. 71): a substituição da força de trabalho veterana por jovens jornalistas, uma vez que profissionais recém-formados se adaptam mais a rotinas multifuncionais e salários mais baixos.

Já se considerarmos nossos dados pela perspectiva geracional (DIMOCK, 2019, p. 1-7), o fato de termos mais da metade dos respondentes entre os millennials (os " $Y$ ") denota que 
tais profissionais, já incluídos digitais quando dedicados à tecnologia do trabalho jornalístico, não teriam sofrido decréscimo em sua performance laboral se esta foi restrita ao uso da web, se mantivermos a hipótese de que já o faziam antes da restrição de mobilidade.

Enquanto à segunda parcela mais significativa da mostra, os $26,6 \%$ de geração $X$, um grupo com maior interesse em crescimento profissional e dedicados ao trabalho como um todo, também é de se esperar que estivessem preparados à uma dedicação mais intensa ao trabalho jornalístico em momento de emergência como é de uma pandemia. Mais acentuados no nativismo digital que os dois extratos geracionais compõem mais de metade da mostra, a geração Z, os pós-millennials, configuram a terceira parcela de profissionais respondentes.

Podemos considerar, portanto, que os respondentes da amostra tinham as características geracionais propícias para se adaptarem às mudanças consideráveis na rotina de trabalho que a cobertura sobre o Coronavírus Ihes impôs. Entretanto, a questão geracional pode ser vista por critérios variados, como pela relação número de horas $\mathrm{x}$ idade ou antiguidade na carreira, ou pela experiência para a tomada de decisão no momento da escolha das fontes, ou ainda pelas emoções geradas sobre os jornalistas neste momento de pressão. Além disso, o fato de serem jovens pode tê-los afetado de forma diferente em relação às escolhas para confinamento ou não durante o período pandêmico, já que se percebeu ao longo de 2020 as taxas de periculosidade do Coronavírus segundo as faixas etárias.

$\mathrm{O}$ corte geracional da amostra enquanto perfis $\mathrm{X}, \mathrm{Y}$ ou $\mathrm{Z}$ corrobora com os dados que indicam o processo de apuração a partir dos recursos digitais ter sido ainda mais intensificado com as restrições ao trabalho de campo. Entretanto, é prudente considerar que o aumento do teletrabalho tenha ocorrido por razões de confinamento, o que se teria comprovado através de uma alteração da metodologia, acrescendo a vertente qualitativa. Sabe-se, contudo, que a verificação de dados pela web não é uma característica específica deste momento do jornalismo. Adghirni (2010, p. 71) observa um modelo de produção de notícias baseado nas ferramentas de informatização há pelo menos duas décadas.

A informatização das redações a partir dos anos 90 contribuiu para que jornalistas assumissem tarefas que antes eram reservadas a técnicos. A emergência de um "jornalismo sentado" (trabalho limitado ao tratamento de notícias de agências e consultas a sites institucionais), o uso do telefone e da internet sem precisar sair da redação foi determinante para reduzir a autonomia dos jornalistas diante das fontes. (ADGHIRNI, 2010, p.71) 
O jornalismo realizado em casa, porém, não diminui o tempo de atuação do jornalista, pelo contrário. Como é de se esperar do processo de precarização do trabalho digitalizado, a atividade exercida por plataforma digital, exercida pela maioria de nossos respondentes, tende a crescer e se consolidar como regular na rotina laboral. A falta de barreiras temporais e espaciais possibilitada pelo trabalho em redação deixou de existir durante o confinamento pandêmico.

Em estudo realizado com 44 jornalistas de São Paulo, Heloani (2006, p. 171-198) concluiu que já no começo dos anos 2000 a carga horária de trabalhadores-jornalistas "superava em muito as prescrições legais às quais essa categoria profissional está submetida, cinco horas diárias acrescidas de mais duas horas extras" (2006, p. 187). Se somarmos a isso à desregulamentação profissional estabelecida pelo Superior Tribunal Federal (STF) em 2010, com a derrubada da exigência do diploma e do registro profissional para exercício do jornalismo; à incorporação de habilidades multifuncionais ao perfil do trabalhador; e ao cenário de hiperconcorrência profissional (ADGHIRNI, 2010, p. 72).

Podemos inferir que o aumento da carga horária de trabalho dos profissionais envolvidos na cobertura da Covid-19 se dá dentro de uma rotina que já era sobrecarregada antes mesmo da pandemia, o que faz com que a situação desses profissionais - mesmo em regime de teletrabalho - fique ainda mais precária. Além dos jornalistas que trabalham na imprensa, os respondentes que configuram quase 50\% das respostas (365 totais, 227 válidas) se distribuem entre modalidades como assessoria de imprensa, comunicação corporativa, agências de publicidade, entre outras. Essa outra metade da amostra se encaixa num cenário que se configura no Brasil desde os anos 80 , com o início do boom das agências de informação direcionadas a nichos específicos, onde muitos jornalistas migraram para outras áreas, sobretudo em empresas que utilizam as habilidades jornalísticas para outros fins. (MICK ; LIMA, 2013, p. 48).

Nossa amostra dialoga com a visão dos autores, ao apresentar três grupos tecnicamente idênticos em quantidade, onde o primeiro se refere aos jornalistas inseridos em veículos de imprensa noticiosa, enquanto que o segundo grupo é formado por jornalistas, mas que não atuam como produtores de notícia, e sim em empresas de geração de mídia e/ou conteúdo. Como estes últimos têm conhecimento conceitual e prático sobre processos e rotinas jornalísticas - ainda que não exerçam tais competências para a geração de notícias, inferimos que estes se tornam um elo entre os profissionais que estão diretamente 
envolvidos com a cobertura da pandemia e o grupo de não-jornalistas consumidores regulares de notícia.

Mesmo que um terço dos respondentes (repórteres na rua e profissionais que frequentam a empresa) representa a parcela de profissionais em maior exposição por atestar que trabalham fora de casa, a necessidade de distribuição de equipamentos de proteção individual se estendeu à maioria dos profissionais respondentes da mostra.

Apesar de o trabalho feito a partir de casa já não ser algo novo para os profissionais que atuam no jornalismo já que nas últimas décadas, o teletrabalho tem sido ainda mais comum principalmente entre os profissionais freelancers e PJs (Pessoas Jurídicas, trabalhadores autônomos). Assim como atesta Fígaro (2013, p. 07-143), "os contratos realizados pelas empresas com jornalistas, tendo-os como pessoa jurídica, e eximindo-se dos tributos relativos aos direitos sociais dos trabalhadores", parece que as empresas noticiosas mantiveram a identificação do ofício à necessidade da mobilidade ocasional, seja para apurar fatos ou checar dados, fazendo com que os jornalistas tenham de deslocar-se em diferentes ocasiões e necessidades, seja oferecendo equipamentos de proteção ao novo Coronavírus. Os dados da nossa amostra indicam consonância com essa realidade.

No que se refere às alterações nas rotinas de trabalho, estas também se refletem nos processos produtivos. O jornalismo, como um objeto em movimento e que está a todo tempo se adaptando a novos cenários, (DEUZE ; WITSCHGE, 2016, p. 06-21) depara-se agora com a necessidade de adaptar suas formas de produção de informação a um cenário de distanciamento social e restrições impostos pela pandemia.

A noticiabilidade, por exemplo, pode ser definida como os requisitos necessários que os eventos devem apresentar para alcançarem o status de notícia (WOLF ; DE FIGUEIREDO, 1987, p. 95). Quando um evento se torna um "acontecimento jornalístico", ele recebe atenção hegemônica no noticiário (MESQUITA, 2003, p. 53). É o que se observa neste caso da cobertura jornalística sobre a pandemia do novo Coronavírus. Se considerarmos que o assunto - num cenário de normalidade - seria tratado em editorias de saúde e ciência com mais regularidade, em contexto pandêmico, causou o envolvimento de pelo menos três quartos das equipes para tratar do tema.

Independente de tê-lo feito dentro de suas editorias ou se realizaram cobertura pautada nos critérios de importância dados pela OMS, o fato é que a alteração do eixo noticioso para um único assunto é digno de coberturas de exceção, como quando há guerras. 
Curiosamente, tal mudança radical se deu a partir de um dos critérios mais clássicos de noticiabilidade: a quantidade de envolvidos. É possível afirmar que não houve na história mundial evento que afetasse simultaneamente nem geograficamente todos os habitantes do planeta. As epidemias e batalhas que já foram cobertas pela imprensa tiveram regiões ou períodos específicos. A tecnologia da informação - além da médica, mapeou a mobilidade de um vírus em tempo real, o que fez reagir o jornalismo de forma a acompanhar tal fenômeno, total.

Finalmente, o principal motivo para que jornalistas recorram a fontes regulares e institucionais, segundo Traquina (2005, p. 88), é o fato de o trabalho jornalístico ser vinculado ao fator tempo. No caso da cobertura sobre o novo Coronavírus, em que os primeiros meses da pandemia foram assustadores, posto que incompreensíveis em um primeiro momento, a velocidade do contágio acelerou o tempo de produção e a quantidade de notícias despendidas pela sociedade. Assim, um ambiente tão volátil quanto incerto fez com que a classe jornalística trabalhasse combinando maioritariamente as figuras públicas com alguma capacidade, envolvimento ou notoriedade para reportar informações à sociedade: gestores públicos, especialistas em saúde, representantes da OMS e população atingida, que fizeram o papel de atores de uma cobertura de um fato único, mas sem nenhuma certeza do que é certo ou verdadeiro, dado o ineditismo do fenômeno abordado e da mutabilidade do vírus.

\section{Considerações}

Este artigo pretendeu apresentar o perfil de uma parcela de jornalistas que cobriram a pandemia de Covid-19. Como limitações ao nosso estudo, ressaltamos a regionalidade de nossos resultados (proeminentemente de São Paulo, capital) e da amostra ser quase que restrita a uma parcela jovem dos profissionais atuantes, além da metodologia, que utilizou apenas coleta quantitativa de dados. Esperamos, porém, termos oferecido contributo para que outras investigações deem prosseguimento ao tema, como por exemplo, com amostras estatísticas de outras regiões do Brasil e com pesquisa qualitativa, o que diminuiria as generalizações de nossos resultados. Além disso, sugerimos outros aportes de investigação, como um estudo sobre os efeitos psicológicos e emocionais que acometeram os jornalistas confinados durante a pandemia de Covid-19 (o que certamente terá alterado processos produtivos), ou as consequências do confinamento, quarentena e afastamento 
social sobre a juventude que ocupa cada vez mais as redações, fenômeno que comprovamos ao menos em nossa limitada amostra. Finalmente, um estudo com o destaque na precarização do ofício durante e no período pós-pandêmico, fenômeno que tem atingido diversas profissões, sobretudo as que têm relação direta com as atividades dentro de plataformas digitais, e especialmente sobre as mulheres, que sofrem com as consequências de uma sociedade patriarcal. Nosso inquérito, ainda que com resultados limitados, é inspirado em um dos estudos mais completos até então da prática jornalística brasileira em tempos de pandemia (FIGARO, 2020), que chegou a resultados reveladores sobre home office e gênero dos respondentes, da profissão e as suas atividades durante a pandemia, o trabalho remoto e trabalho digital. Ainda que de forma menos eloquente, espera-se que o resultado de nosso trabalho tenha contribuído de alguma forma para a confirmação ou para a descoberta de como está se configurando a cobertura da pandemia de Covid-19 no Brasil.

Segundo Fígaro (2020), a maioria dos respondentes de seu estudo são jornalistas do gênero feminino com idade entre 19 e 39 anos. Numericamente, a maioria atua em mídia tradicional: assessoria de comunicação e agência de comunicação; poucas empresas supriram o home office dos trabalhadores com ferramentas adequadas para 0 desenvolvimento do trabalho ${ }^{6}$. Houve aumento da jornada de trabalho e intensificação do ritmo de trabalho para a maioria dos respondentes. Os resultados deste trabalho ressaltam a precarização do ofício durante a pandemia.

Em nosso estudo - em que deve ser considerado segundo limitações de mais de duas centenas de respostas válidas, teve na maioria respostas provindas da cidade de São Paulo e cuja a identidade regular de nosso respondente é de jovens, homens ou mulheres, entre 26 e 40 anos, com 1 a 10 anos de carreira, sendo que metade deles trabalha em veículos de imprensa de São Paulo. Esse perfil médio de jornalista não se dedicava à cobertura de temas ligados à saúde ou ciência, mas se adaptou a tal, bem como trabalhar de casa, apurando notícias e checando dados por telefone ou pelo computador. Mesmo assim, sua

\footnotetext{
6 "O custo do uso de infraestrutura da residência do trabalhador ainda não foi computado, porque certamente as contas de energia elétrica, internet e telefone chegarão nos próximos meses. Também o custo com equipamentos, softwares fica na conta do trabalhador." (FÍGARO. 2020, p.72)
} 
empresa Ihe forneceu equipamento de segurança contra o contágio do novo Coronavírus. O profissional de nosso perfil se dedicou mais ao trabalho que regularmente, tendo sua rotina alterada pela pandemia. Sofreu constrangimentos para a execução do trabalho, mas apenas em poucas situações foi impedido de exercer a prática jornalística, seja por restrições ocasionais, técnicas ou hediondas.

O perfil médio do nosso respondente é um jornalista produtor de texto, atuante na imprensa, seja para portais web, jornais ou revistas. Utilizou duas a três fontes de informação a cada conteúdo produzido, na maioria das vezes, a OMS, gestores públicos, profissionais da saúde e/ou cientistas. Claramente, observamos que os processos produtivos e as rotinas de trabalho foram alterados consideravelmente em sua temporalidade e espacialidade durante o isolamento e afastamento sociais. Porém, entendemos que processos como a precarização e o aumento do trabalho, o rejuvenescimento dos profissionais nas redações, a digitalização do ofício e a conversão do ambiente laboral para o home office são fenômenos já existentes antes da pandemia, tendo sido acentuados pelo ineditismo da situação pela qual passamos todos os cidadãos do planeta. Resta saber se tais mudanças serão mantidas nas rotinas jornalísticas e irão configurar o "novo normal" das rotinas produtivas e processos jornalísticos, que comporão o perfil profissional dos jornalistas no pós-Covid, seja ele quando for.

\section{Referências}

ADGHIRNI, Zélia Leal; PEREIRA, Fábio Henrique. Mudanças estruturais no jornalismo: alguns apontamentos. Encontro Nacional de Pesquisadores em Jornalismo, 2010. . Rotinas produtivas do jornalismo em BrasíliaObservações sobre o processo de produção da notícia na área política e econômica de três jornais na capital federal: O Globo, Folha de S. Paulo e Correio Braziliense.

MOUILLAUD, Maurice; PORTO, Sérgio Dayrell. O jornal: da forma ao sentido. Brasília: Paralelo, v. 15, 1997.

BRANDALISE, C.; ROVANI, A. 100 DIAS QUE MUDARAM O MUNDO: Para a historiadora Lilia Schwarcz, a pandemia marca fim do século 20 e indica os limites da tecnologia. Universa/UOL. Acesso em 06/08/2020. Disponibilizado em https://www.uol.com.br/universa/reportagens-especiais/coronavirus-100-dias-quemudaram-o-mundo/index.htm

CAPOANO, E.; COSTA, P. D. Inquérito Percepção sobre as informações geradas durante o Covid-19. Acesso em julho de 2020. Disponibilizado em Google Forms: 2020. Disponível em https://forms.gle/nZ8Y9Fn5FFqouuog8 e https://forms.gle/17hRQhTiMLaCpyCz5.

DE REZENDE, Joffre Marcondes. Epidemia, endemia, pandemia, epidemiologia. Revista de Patologia Tropical/Journal of Tropical Pathology, v. 27, n. 1, 1998. 
DEUZE, Mark; WITSCHGE, Tamara. O que o jornalismo está se tornando. Parágrafo, v. 4, n. 2,, 2016.

DIMOCK, Michael. Defining generations: Where Millennials end and Generation Z begins. Pew Research Center, v. 17, 2019.

FIGARO, Roseli et al. Como trabalham os comunicadores na pandemia do Covid19?. Revista Jurídica Trabalho e Desenvolvimento Humano, v. 3, 2020.

. Perfis e discursos de jornalistas no mundo do trabalho. As mudanças no mundo do trabalho do jornalista, 2013.

FRAGA, E. 2020. Descontentamento com Bolsonaro na pandemia pode levar país a conflagração, diz Eduardo Giannetti. Jornal Folha de S. Paulo. Acesso em 06/08/2020. Disponibilizado em https://www1.folha.uol.com.br/mercado/2020/03/descontentamentocontra-bolsonaro-na-pandemia-pode-levar-pais-a-conflagracao-diz-eduardogiannetti.shtml

GHEBREYESUS, T. A. Declaração sobre pandemia do novo coronavírus. Agência de notícias Lusa, 13/11/2020. Acesso em 06/08/2020. Disponibilizado em https://www.sns.gov.pt/noticias/2020/03/11/Covid-19-pandemia/

GIL, J. O medo. Jornal O Público. Acesso em 06/08/2020. Acesso em 06/08/2020. Disponibilizado em https://www.publico.pt/2020/03/15/sociedade/ensaio/medo-1907861

HARARI, Y. N. The world after Coronavirus. Jornal Financial Times, 20/03/2020. Acesso em 06/08/2020. Disponibilizado em https://www.ft.com/content/19d90308-685811ea-a3c9-1fe6fedcca75

HELOANI, Roberto. O trabalho do jornalista: estresse e qualidade de vida. Interações, n. 22, 2006.

INSTITUTO CAMOES. Uma língua grande como os mares. Lisboa: 2019.

JORNAL DA USP. O professor Guilherme Wisnik reflete, em sua coluna, sobre como ficará o mundo pós-pandemia de coronavírus, confrontando duas perspectivas. Jornal da USP. 02/04/2020. Acesso em 06/08/2020. Disponibilizado em jornal.usp.br/?p=311676

MAAKAROUN, M. O modo de funcionamento da humanidade entrou em crise, diz Ailton Krenak. Jornal Estado de Minas, 03/04/2020. Acesso em 06/08/2020, disponibilizado em https://www.em.com.br/app/noticia/pensar/2020/04/03/interna pensar,1135082/funcionam ento-da-humanidade-entrou-em-crise-opina-ailton-krenak.shtml.

MARTINS, Moisés de Lemos et al. Lusofonia e interculturalidade-promessa e travessia. Universidade do Minho. Centro de Estudos Humanísticos (CEHUM), 2015. 
MESQUITA, M. O Quarto Equívoco: o poder dos media na sociedade contemporânea. Coimbra: Minerva Coimbra, 2003.

MICK, J.; LIMA, S. Perfil do jornalista brasileiro: características demográficas, políticas e do trabalho jornalístico em 2012. Florianópolis: Insular, 2013.

MOLLA, R. How coronavírus took over social media. Portal Vox, 12/03/2020. Disponibilizado em https://www.vox.com/recode/2020/3/12/21175570/coronavirus-Covid19-social-media-twitter-facebook-google

SANTOS, B. de S. Vírus: tudo o que é sólido se desfaz no ar. Jornal Público. Acesso em 06/08/2020. Disponibilizado em https://www.publico.pt/2020/03/18/mundo/opiniao/virus-solido-desfaz-ar-1908009

SCURATI, A. Milão. A cidade mais privilegiada de Itália está agora na fila do pão. Jornal Observador, 25/03/2020. Acesso em 06/08/2020. Disponibilizado em https://observador.pt/especiais/milao-a-cidade-mais-privilegiada-de-italia-esta-agora-nafila-do-pao/

SOLOMON, A. When the Pandemic Leaves Us Alone, Anxious and Depressed. Jornal The New York Times, 09/04/2020. Acesso em 06/08/2020. Disponibilizado em https://www.nytimes.com/2020/04/09/opinion/sunday/coronavirus-depression-anxiety.html TRAQUINA, Nelson. Teorias do jornalismo. Insular, 2005.

VEIGA, E. Isolado em SP, cineasta Fernando Meirelles afirma que a pandemia é 'titica' se comparada à crise do clima. Portal UOL TAB. Acesso em 06/08/2020. Disponibilizado em https://tab.uol.com.br/edicao/fernando-meirelles/index.htm

VELAVAN, T. P.; MEYER, Christian G. The Covid $\square 19$ epidemic. Tropical medicine ; international health, v. 25, n. 3, p. 278, 2020. Acesso em 06/08/2020. Disponibilizado em https://www.ncbi.nlm.nih.gov/pmc/articles/PMC7169770/

WOLF, Mauro; DE FIGUEIREDO, Maria Jorge Vilar. Teorias da comunicação. Presença, 1987.

ZIZEK, S. Zizek vê o poder subversivo do Coronavírus. Portal Outras Palavras, 03/03/2020. Acesso em 06/08/2020. Disponibilizado em https://outraspalavras.net/crisecivilizatoria/zizek-ve-o-poder-subversivo-do-coronavirus/

ZU, Z.Z. et al. Coronavirus disease 2019 (Covid-19): a perspective from China. Radiology, p. 200490, 2020. Acesso em 06/08/2020. Disponibilizado em https://www.em.com.br/app/noticia/pensar/2020/04/03/interna pensar,1135082/funcionam ento-da-humanidade-entrou-em-crise-opina-ailton-krenak.shtml

Submissão: 25 out. 2020

Aceite: 10 jan. 2021 